\title{
Prevalence of NIDDM and impaired glucose tolerance in Italy: an OGTT-based population study
}

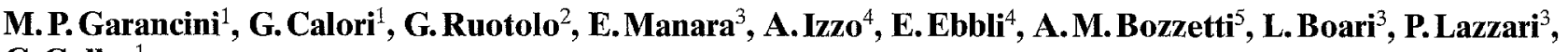 \\ G. Gallus ${ }^{1}$ \\ ${ }^{1}$ Medical Statistics and Epidemiology Unit, Medical School, University of Milan, S. Raffaele Scientific Institute, Milan, Italy \\ 2 Lipid Metabolism Laboratory, S. Raffaele Scientific Institute, Milan, Italy \\ ${ }^{3}$ Hospital of Cremona, 51th Local Health District of Lombardy, Cremona, Italy \\ ${ }^{4}$ Staff District Office, 51st Local Health District of Lombardy, Cremona, Italy \\ ${ }^{5}$ Casalbuttano Health District, 51st Local Health District of Lombardy, Casalbuttano, Italy
}

Summary To provide complete prevalence data on diabetes mellitus in Italy (diagnosed and undiagnosed), a population survey was performed in the Health District of Cremona, a representative area of the Po river (north Italy). The survey is characterised by particular attention being paid to methodology, non-responders being investigated for possible selection biases affecting diagnosed and undiagnosed diabetes prevalence estimations. Out of a population aged 44 years or older from three municipalities, a random sample of 3097 subjects was selected to undergo an oral glucose tolerance test. In addition, past medical history, clinical and laboratory data were collected. A total of 1797 subjects participated (58\%), and information on known diabetes status was obtained for 2618 persons ( $85 \%$ ), also including 826 interviewed non-participating subjects. Overall rates were age-standardised according to the 1991 Italian census. Overall prevalence and $95 \%$ confidence interval of diagnosed diabetes was $8.5 \%(6.9-10.1)$ in males and $7.9 \%(6.7-9.3)$ in females over the age of 44 years; previously undiagnosed diabetes was $2.5 \%$ $(1.4-3.6)$ in males and $3.4 \%(2.1-4.7)$ in females; glucose intolerance was $7.7 \%(5.7-9.7)$ in males and $8.9 \%(7.0-10.8)$ in females. Total diabetes prevalence above age 44 years, developed-world age, and sex standardised, was $10.7 \%$. This study provides the first reliable prevalence estimation of impaired glucose tolerance, diagnosed and undiagnosed diabetes in Italy, according to World Health Organization criteria, and one of the few figures for Southern Europe. The role of body mass index on both prevalence of diabetes and cluster of cardiovascular risk factors is considered, with implications for prevention. [Diabetologia (1995) 38: 306-313]

Key words Population surveillance, prevalence, noninsulin-dependent diabetes mellitus, glucose intolerance, glucose tolerance test.
In spite of the increasing amount of data on known diabetes mellitus, oral glucose tolerance test (OGTT)-based population studies (World Health Organization criteria) are still rare, and accurate

Received: 24 February 1994 and in revised form 9 June 1994

Corresponding author: Professor G.Gallus, Epidemiology Unit, S. Raffaele Institute, DIBIT, via Olgettina, 58, I-20132 Milan, Italy.

Abbreviations: OGTT, Oral glucose tolerance test; BMI, body mass index; C.I., confidence intervals. evaluations of both diagnosed and undiagnosed diabetes are almost absent in the literature, particularly for the southern part of Europe [1]. This situation should be compared with the importance of a proper knowledge of the extent of this disease for prevention strategy, given the association of diabetes with cardiovascular mortality.

In this context, we carried out a large population survey in the Health District of Cremona, in order to estimate the prevalence of diagnosed and undiagnosed diabetes and impaired glucose tolerance in north Italy, and to set up a population cohort in anticipation of a follow-up study. 


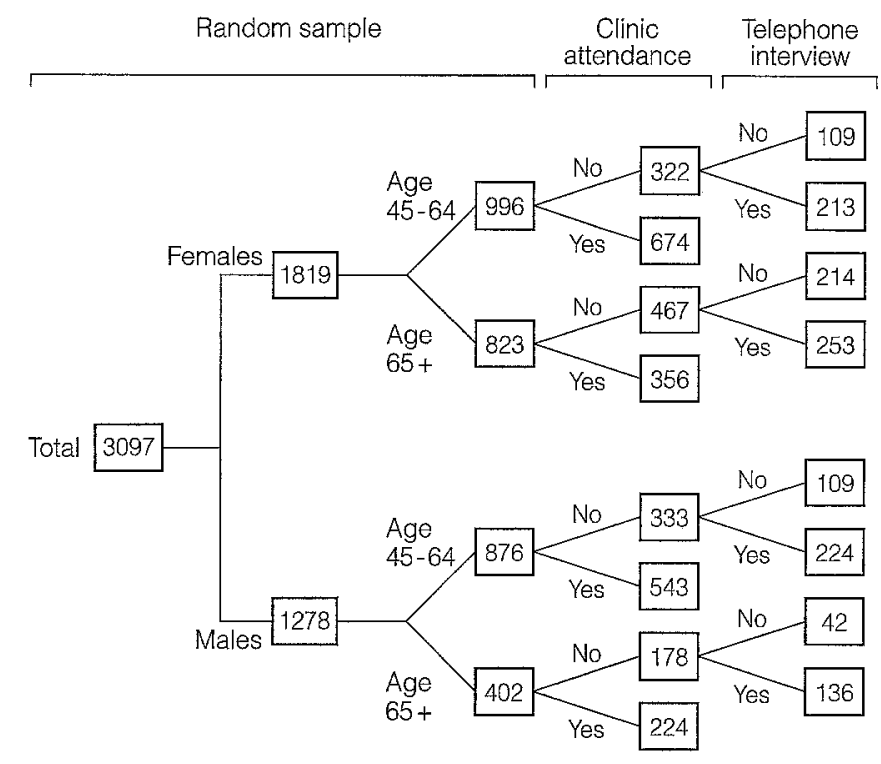

Fig. 1. Study population by level of participation, age and sex

\section{Subjects and methods}

The study consisted of a population survey carried out in 1990 in the Health District of Cremona (51st Local Health District of Lombardy). The present study involves 3097 subjects aged 45 years or over, randomly selected from 38,634 inhabitants of three representative municipalities of the Health District (Cremona, Casalbuttano, and Vescovato), as registered in the Lombard Regional Computer Service. Institutionalised subjects were excluded from the randomisation (about $2 \%$ of the reference population).

After an information campaign, all the selected subjects were invited to visit one of the three clinics set up for this programme (one in each town). At the clinic fasting venous blood was sampled (after at least a 12-h overnight fast), a 75 -g oral glucose monohydrate was given, past medical history was taken and clinical data were collected through a standard proto$\mathrm{col}$, and a further venipuncture 2-h after the glucose load. This phase was completed in a 9-month period, following 2 April 1990.

For plasma glucose determinations, blood was collected into tubes with a glycolytic inhibitor and analysed within 3 to $4 \mathrm{~h}$ in a central laboratory through the GOD-PAP glucose-oxidase method (Boehringer Mannheim, Milan, Italy) with a Hitachi 705 autoanalyser (Hitachi, Tokyo, Japan). At the same time fibrinogen, GOT, GPT, gammaGT and ALP were also determined. A further $20 \mathrm{ml}$ of fasting blood was immediately centrifuged and plasma was stored at $-30^{\circ} \mathrm{C}$ in five different tubes; they were then transferred in dry ice to the other central laboratory for insulin, total and HDL-cholesterol, triglycerides and lipoprotein(a) determinations.

Insulin was determined by a radioimmunoassay method (intraassay and interassay coefficients of variation were $6.0 \%$ and $5.3 \%$, respectively) (kit Technogenetics, Medgenics, Brussels, Belgium). Total cholesterol and triglycerides were measured by enzymatic methods (Boehringer Mannheim, Mannheim, Germany) with the CIBA Corning 550 Express Autoanalyser. The HDL fraction was separated from plasma by precipitation with PEG using a Colortest kit (Roche, Basel, Switzerland). Lipoprotein(a) concentration was quantified using a commercially available ELISA kit (Tint Elize Lp(a) kit, Biopool, Umea, Sweden), intraassay coefficients of variation of li- poprotein(a) concentrations of 40 and $300 \mathrm{mg} / \mathrm{dl}$ were $3.8 \%$ and $2.1 \%$, respectively whereas interassay coefficients of variation were $8.5 \%$ and $3.6 \%$, respectively.

Anthropometric measures (height, weight, waist and thigh girths) were taken by the same trained person using the same instruments for all the investigated subjects. The waist to thigh ratio was calculated as an index of fat distribution. Heart rate and systolic and diastolic blood pressures were taken twice, at the beginning and at the end of the visit, in the sitting position and after at least $10 \mathrm{~min}$ rest. The lowest figure was considered. Measures were obtained using a full automatic non-invasive sphygmomanometer (BP-103N Nippon Colin Co., Colin Corporation, Hayashi, Komakisiti, Japan). Further details concerning the study protocol have been already reported previously [2].

Diabetes was either defined according to a previously known diabetes status (i.e. on hypoglycaemic drug therapy or with a proved diagnosis of diabetes) or according to the results of the OGTT [3]. It was then classified as already diagnosed or previously undiagnosed diabetes, respectively. Subjects with diagnosed diabetes did not undergo the OGTT. Diabetic subjects diagnosed below age 30 years and on insulin therapy were considered as insulin dependent.

Hypercholesterolaemia was defined as total cholesterol above $5.7 \mathrm{mmol} / \mathrm{l}$ while hypertriglyceridaemia as triglycerides above $1.9 \mathrm{mmol} / \mathrm{l}$. To provide a possibly unbiased prevalence estimation of total diabetes, efforts were made to obtain information on known diabetes status among non-responders: the prevalence of diagnosed diabetes was then adjusted to compensate for respondence status by weighting the frequency of diabetes among responders and non-responders for the response proportion in each 10-year stratum of age, by sex.

Results are reported both as age- and sex-specific prevalence and as overall prevalence, and $95 \%$ confidence intervals (C.I.) were calculated. The overall prevalence was standardised by age and sex using the 1989 Health Regional files of the adult population of Casalbuttano, Vescovato and Cremona together, hospice living excluded. To provide a national agestandardised result, overall prevalence was calculated also according to the 1991 Italian census [4]. The overall diabetes prevalence is also reported after age standardisation according to the world standard population of the more developed countries [5].

Population data of the frequency distribution of serum fasting insulin (after exclusion of the insulin-treated subjects), total cholesterol, HDL-cholesterol and triglycerides levels are reported. Age-standardised hypercholesterolaemia and hypertrigliceridaemia prevalences were estimated. The population was also characterised in terms of clinical and biochemical data according to the condition of glucose tolerance.

The role of body mass index (BMI) was considered among males and females either by estimating the prevalence of both impaired glucose tolerance and diabetes by degree of obesity $\left(\mathrm{BMI} \leq 27 \mathrm{~kg} / \mathrm{m}^{2}\right.$ or BMI $\left.>27 \mathrm{~kg} / \mathrm{m}^{2}\right)$ or through a logistic regression analysis (dependent variable: diabetes or glucose intolerance vs normal; independent variables: age, degree of obesity and waist to thigh ratio). The relationship between common cardiovascular risk factors and clustering in syndrome X, was evaluated by comparing the pattern of subjects with low ( $<50$ th centile) vs high ( $\geq 50$ th centile) fasting insulin levels. Multiple regression models have been applied to evaluate the role of BMI and waist to thigh ratio. In all the comparison analyses insulin, triglycerides and lipoprotein(a) data have been processed after Log transformation. 
Table 1. Frequency of previously diagnosed diabetes and of family history among subjects without diagnosed diabetes: comparison between clinic attenders and non-attenders ${ }^{\mathrm{a}}$

\begin{tabular}{lllllll}
\hline & $\begin{array}{l}\text { Age } \\
\text { (years) }\end{array}$ & Males & & & Females & \\
\cline { 3 - 4 } & $\begin{array}{l}\text { Diagnosed diabetes } \\
n(\%)\end{array}$ & $\begin{array}{l}\text { Family history } \\
n(\%)\end{array}$ & & $\begin{array}{l}\text { Diagnosed diabetes } \\
n(\%)\end{array}$ & $\begin{array}{l}\text { Family history } \\
n(\%)\end{array}$ \\
\hline Attenders & $45-64$ & $44(8.1)$ & $118(23.9)$ & & $31(4.6)$ & $201(31.7)$ \\
& $65+$ & $21(9.4)$ & $23(11.4)$ & & $45(12.6)$ & $73(24.1)$ \\
Non-attenders & $45+^{\mathrm{b}}$ & $65(8.5)$ & $141(19.9)$ & & $76(8.8)$ & $274(27.5)$ \\
& $45-64$ & $17(7.6)$ & $33(16.5)$ & & $15(7.0)$ & $37(18.8)$ \\
& $65+$ & $14(10.3)$ & $13(11.0)$ & & $26(10.3)$ & $18(8.1)$ \\
& $45+^{\mathrm{b}}$ & $31(8.7)$ & $46(14.9)$ & & $41(8.6)$ & $55(13.9)$ \\
\hline
\end{tabular}

a Information collected by telephone interviews

${ }^{b}$ Age-standardised according to the Cremona Health District population

Table 2. Prevalence of IGT, undiagnosed and diagnosed diabetes

\begin{tabular}{|c|c|c|c|c|c|c|c|c|}
\hline \multirow[t]{2}{*}{ Age (years) } & \multicolumn{2}{|l|}{ IGT } & \multicolumn{2}{|c|}{ Undiagnosed diabetes } & \multicolumn{2}{|c|}{ Diagnosed diabetes } & \multicolumn{2}{|c|}{ Total diabetes } \\
\hline & $\begin{array}{l}\text { Males } \\
n(\%)\end{array}$ & $\begin{array}{l}\text { Females } \\
n(\%)\end{array}$ & $\begin{array}{l}\text { Males } \\
n(\%)\end{array}$ & $\begin{array}{l}\text { Females } \\
n(\%)\end{array}$ & $\begin{array}{l}\text { Males } \\
n(\%)\end{array}$ & $\begin{array}{l}\text { Females } \\
n(\%)\end{array}$ & $\begin{array}{l}\text { Males } \\
n(\%)\end{array}$ & $\begin{array}{l}\text { Females } \\
n(\%)\end{array}$ \\
\hline $45-54$ & $14(5.1)$ & $\begin{array}{l}12(3.7) \\
25(72)\end{array}$ & $\begin{array}{l}4(1.5) \\
4(1.5)\end{array}$ & $4(1.2)$ & $18(4.5)$ & $\begin{array}{l}13(3.2) \\
33(7.5)\end{array}$ & $22(6.0)$ & $17(4.4)$ \\
\hline $55-64$ & $15(5.6)$ & $25(7.2)$ & $4(1.5)$ & $7(2.0)$ & $43(11.6)$ & $33(7.5)$ & $47(13.1)$ & $40(9.5)$ \\
\hline $65-74$ & $16(9.5)$ & 27 (11.1) & $9(5.4)$ & $11(4.5)$ & $23(9.3)$ & $39(10.9)$ & $31(14.7)$ & $50(15.4)$ \\
\hline $75+$ & $11(20.0)$ & $21(18.9)$ & $1(1.8)$ & $10(9.0)$ & $12(10.8)$ & $32(11.8)$ & $13(12.6)$ & $42(20.8)$ \\
\hline $45 t^{b}$ & $56(7.7)$ & $85(8.9)$ & $18(2.5)$ & $32(3.4)$ & $96(8.5)$ & $117(7.9)$ & $114(11.0)$ & 149 (11.3) \\
\hline $95 \%$ Confidence Interval & $(5.7-9.7)$ & $(7.0-10.8)$ & $(1.4-3.6)$ & $(2.1-4.7)$ & $(6.9-10.1)$ & $(6.5-9.3)$ & $(9.3-12.7)$ & $(9.8-12.8)$ \\
\hline
\end{tabular}

Total diabetes prevalence was $10.6 \%$ for males and $10.8 \%$ for females after age-standardisation for developed-world population.
${ }^{a}$ Adjusted for non-participation

${ }^{\mathrm{b}}$ Age-standardised according to the Italian population (census 1991)

\section{Statistical analysis}

All the analyses were performed using the SAS software. Comparisons between frequencies were performed through Fisher's exact test and chi-square test. Relative risks adjusted for stratification variables were estimated as Mantel-Haenszel risks. All the clinical and biochemical data comparisons were properly adjusted through the covariance analysis performed by the generalized linear model (GLM).

\section{Results}

After efforts to increase compliance, 1797 subjects (767 males and 1030 females) agreed to participate out of a total randomised sample of 3097: overall participation to visit was $58 \%$. Participation resulted in a similar response in the different age strata, for both sexes, except among the elderly, where males participated more than females (Fig. 1). About $67 \%$ of non-participants showed little interest, $11 \%$ had lack of free time or job reasons, $16 \%$ were severely infirm, $2 \%$ were sick at the time of the screening and about $4 \%$ had died in the meantime.

Out of the 1300 non-participants, 826 were traced and interviewed by telephone about their status of diagnosed diabetes. Finally, information on diagnosed diabetes was available for 2618 subjects representing $85 \%$ of the randomised sample. The proportion of previously diagnosed diabetes between participants and interviewed non-participants who visited the surgery are shown in Table 1 in different age and sex strata. In order to evaluate possible prevalence estimation bias also regarding impaired glucose tolerance and undiagnosed diabetes, we investigated the subjects with no previous diagnosis of diabetes about their family history of diabetes according to the participation in attending the clinic (Table 1). Family diabetes history appeared to be more frequent among participants than among interviewed non-participants across the different age and sex strata, but neither undiagnosed diabetes nor impaired glucose tolerance among participants in the clinic visit was significantly associated with a reported status of family history of diabetes. It was then decided not to adjust impaired glucose tolerance and undiagnosed diabetes figures for non-participation.

Overall prevalence above 45 years of age was $7.7 \%$ (5.7-9.7) and $8.9 \%$ (7.0-10.8) for impaired glucose tolerance, $2.5 \%(1.4-3.6)$ and $3.4 \%(2.1-4.7)$ for previously undiagnosed diabetes, and $8.5 \%$ (6.9$10.1)$ and $7.9 \%(6.5-9.3)$ for already-diagnosed diabetes for males and females, respectively. Age and sex specific prevalence data for each of these conditions are reported in Table 2 . These data show a consistently increasing trend with age and a general tendency to higher frequency among younger males and 
Table 3. Prevalence of overweight and proportion ${ }^{a}$ of diabetes (diagnosed and undiagnosed) and glucose intolerance among responders, by degree of obesity

\begin{tabular}{|c|c|c|c|c|c|}
\hline \multirow[t]{2}{*}{ Age (years) } & \multirow{2}{*}{$\begin{array}{l}\text { Obesity } \\
\left(\mathrm{BMI}>27 \mathrm{~kg} / \mathrm{m}^{2}\right) \\
n(\%)\end{array}$} & \multicolumn{2}{|l|}{ Diabetes } & \multicolumn{2}{|l|}{ Diabetes + IGT } \\
\hline & & $\begin{array}{l}\mathrm{BMI} \leq 27 \mathrm{~kg} / \mathrm{m}^{2} \\
n(\%)\end{array}$ & $\begin{array}{l}\mathrm{BMI}>27 \mathrm{~kg} / \mathrm{m}^{2} \\
n(\%)\end{array}$ & $\begin{array}{l}\mathrm{BMI} \leq 27 \mathrm{~kg} / \mathrm{m}^{2} \\
n(\%)\end{array}$ & $\begin{array}{l}\mathrm{BMI}>27 \mathrm{~kg} / \mathrm{m}^{2} \\
n(\%)\end{array}$ \\
\hline \multicolumn{6}{|l|}{ Males } \\
\hline $45-54$ & $115(42.4)$ & $4(2.6)$ & $13(11.3)$ & $9(6.0)$ & $22(19.0)$ \\
\hline $55-64$ & $129(48.0)$ & $10(7.3)$ & $25(19.5)$ & $18(13.1)$ & $32(25.0)$ \\
\hline $65-74$ & $74(44.3)$ & $15(16.1)$ & $10(13.5)$ & $24(29.4)$ & $17(23.0)$ \\
\hline \multicolumn{6}{|l|}{ Females } \\
\hline $45-54$ & $116(35.9)$ & $0(-)$ & $12(10.5)$ & $6(2.9)$ & $18(15.8)$ \\
\hline $55-64$ & $148(42.5)$ & $14(7.1)$ & $16(10.1)$ & $22(11.5)$ & $33(21.6)$ \\
\hline $65-74$ & $108(44.6)$ & $11(8.2)$ & $26(24.1)$ & $24(17.9)$ & $40(37.1)$ \\
\hline $75+$ & $46(40.7)$ & $16(23.8)$ & $13(29.5)$ & $27(40.2)$ & $23(52.2)$ \\
\hline $45+{ }^{b}$ & $418(40.9)$ & $41(9.8)$ & $67(17.7)$ & $69(17.5)$ & $114(31.4)$ \\
\hline
\end{tabular}

a Calculated on 912 males and 1019 females

${ }^{b}$ Age-standardised according to the Cremona Health District population

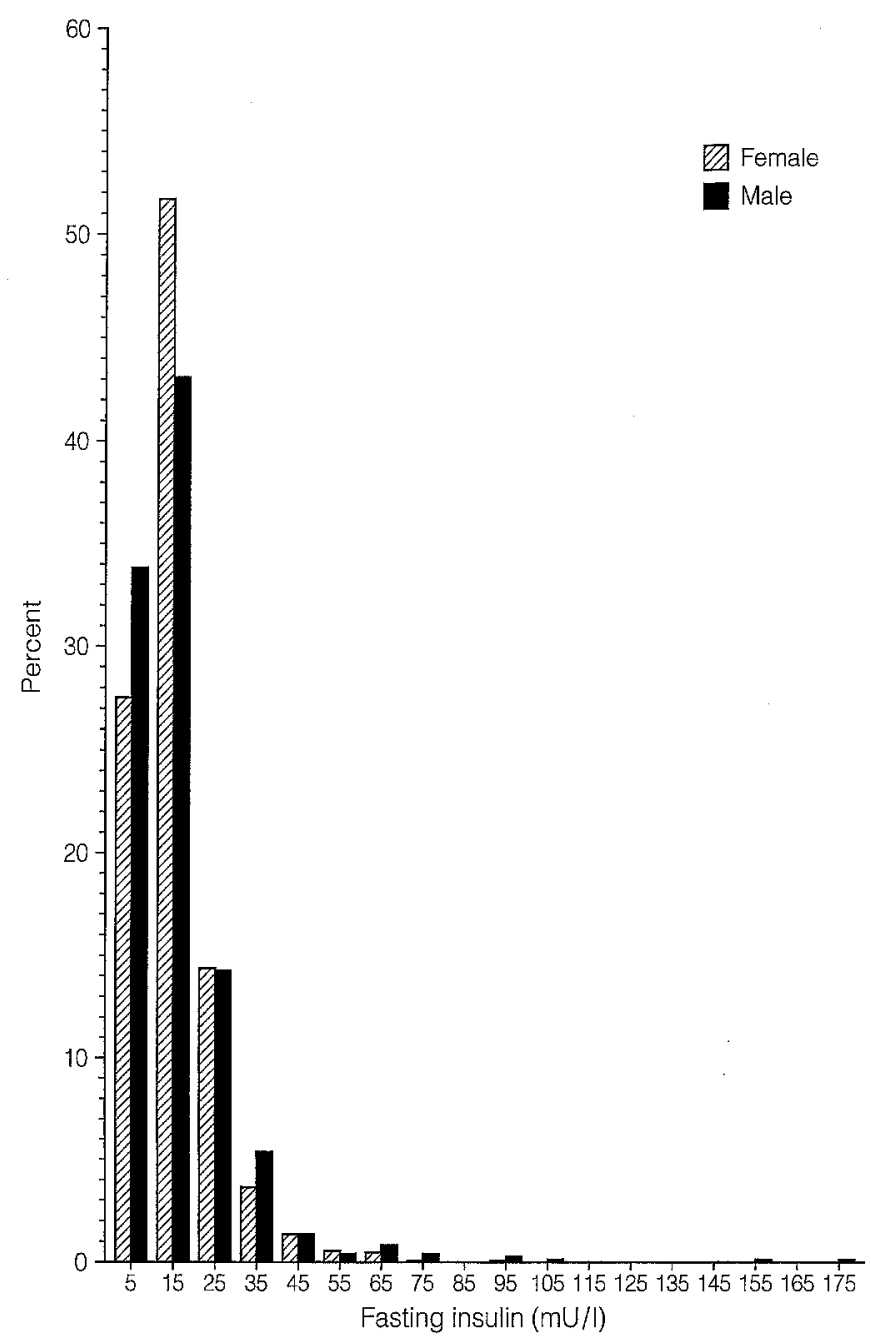

Fig. 2. Frequency distribution of plasma fasting insulin levels in the population above the age of 44 years, by sex Numbers on the $x$-axis are the midpoints. Insulin-treated subjects have been excluded among older females. The relationship between previously undiagnosed and already diagnosed diabetes appears clearly unbalanced towards the latter. No subject was found with insulin-dependent diabetes. Diabetes and glucose intolerance together represented $18.7 \%$ of males and $20.2 \%$ of females, above age 45 years.

Diagnosed and undiagnosed diabetes together resulted in $11.0 \%$ and $11.3 \%$ for males and females, respectively. It was $10.6 \%$ and $10.8 \%$ after world agestandardisation and roughly $3.2 \%$ and $3.9 \%$ over all ages for males and females, respectively. Table 3 shows the frequency of all these conditions among participants by different BMI levels, below or equal to $27 \mathrm{~kg} / \mathrm{m}^{2}$ and above $27 \mathrm{~kg} / \mathrm{m}^{2}$. After age-standardisation, impaired glucose tolerance and diabetes appeared more frequently among obese than non-obese subjects, even if not always significantly. Impaired glucose tolerance and diabetes as a whole represented $25.0 \%$ (males) $-31.4 \%$ (females) of an obese population, whereas its proportion was $13.7 \%$ (males) $-17.5 \%$ (females) among non-obese. Mantel-Haenszel age-adjusted association of obesity was significant both with diabetes alone (relative risks: 2.1 (1.4-3.2) for males and 2.3 (1.6-3.2) for females) and with diabetes and glucose intolerance together (relative risks: 1.8 (1.3-2.4) for males and 2.0 (1.62.6) for females). Logistic regression analysis also showed that diabetes and impaired glucose tolerance were associated with obesity, in both males $(p=0.0039)$ and females $(p<0.0001)$, independently of age and waist to thigh ratio: the odds ratio of these conditions was 1.3 (1.1-1.6) and $1.5(1.3-1.8)$ for obese vs non-obese subjects for males and females, respectively.

Among responders, obesity $\left(\mathrm{BMI}>27 \mathrm{~kg} / \mathrm{m}^{2}\right)$ accounted for $44.6 \%$ and $40.9 \%$ of males and females, respectively, above age of 45 years (Table 3 ). Popula- 


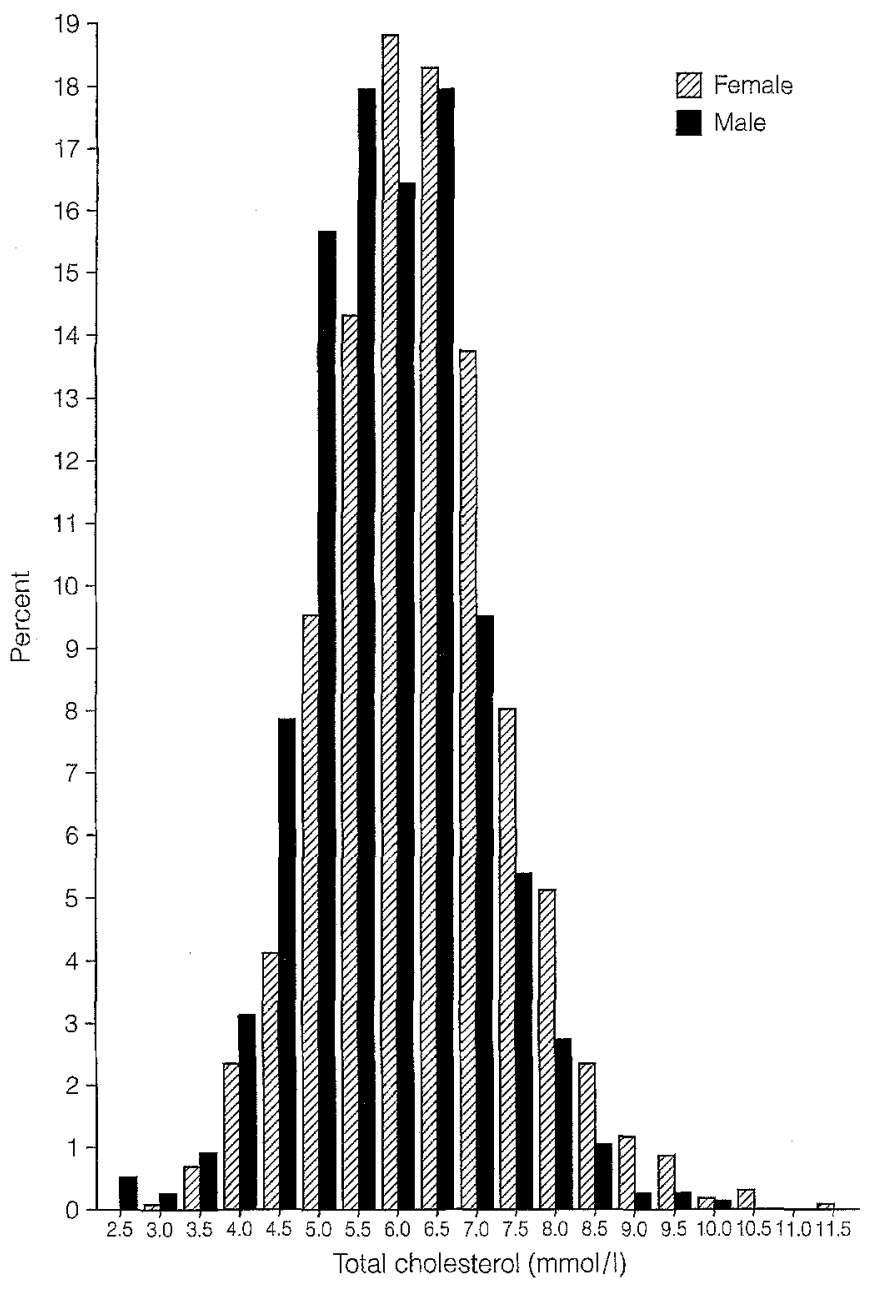

Fig.3. Frequency distribution of plasma total cholesterol levels in the population above the age of 44 years, by sex. Numbers on the $\mathrm{x}$-axis are the midpoints

tion frequency distributions of fasting plasma insulin, total cholesterol, HDL-cholesterol and triglycerides are shown in Figures 2, 3, 4 and 5, respectively. Mean \pm SD of insulin was $16.9 \pm 14.3 \mathrm{mU} / \mathrm{l}$ for males and $16.0 \pm 9.6 \mathrm{mU} / \mathrm{l}$ for females; total cholesterol was $5.90 \pm 1.07 \mathrm{mmol} / 1$ for males and $6.32 \pm 1.14 \mathrm{mmol} / 1$ for females; HDL-cholesterol was $1.26 \pm 0.40 \mathrm{mmol} / \mathrm{l}$ for males and $1.45 \pm 0.36 \mathrm{mmol} / \mathrm{l}$ for females; triglycerides were $1.64 \pm 1.33 \mathrm{mmol} / 1$ and $1.34 \pm 0.66 \mathrm{mmol} / \mathrm{l}$ for males and females, respectively. Age-standardised proportion of hypercholesterolaemia was $56.1 \%$ for males and $71.5 \%$ for females, while hypertriglyceridaemia was $23.9 \%$ for males and $15.3 \%$ for females.

Table 4 shows the age-adjusted comparison of some variables between diabetic, glucose intolerant and normal subjects. All the considered parameters, except for total cholesterol and lipoprotein(a), showed a worsening trend from normal towards diabetic subjects for both males and females. This trend was more evident for females. Total cholesterol was not different among males, whereas it decreased

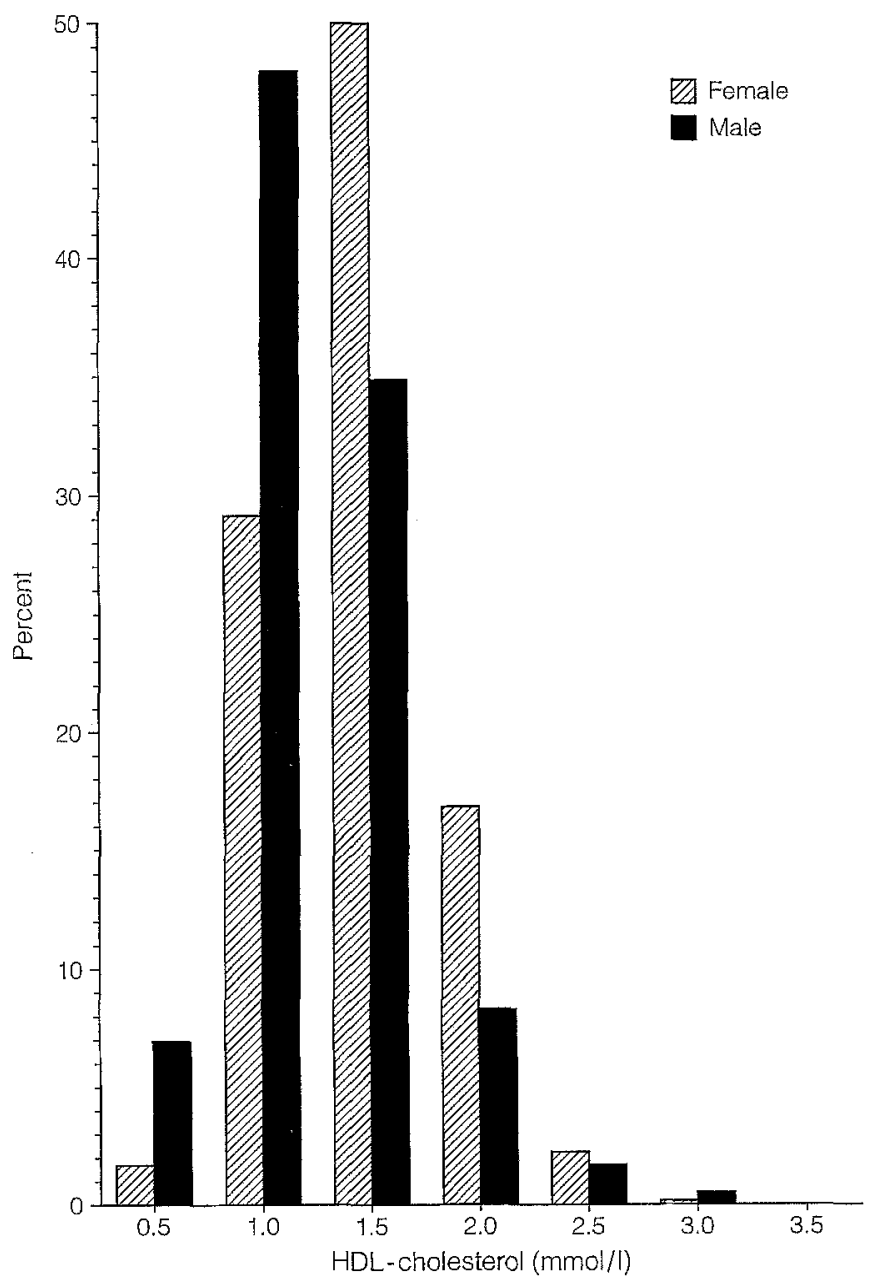

Fig.4. Frequency distribution of plasma HDL-cholesterol levels in the population above the age of 44 years, by sex. Numbers on the $\mathrm{x}$-axis are the midpoints

from normal to diabetic subjects in females. Lipoprotein(a) showed an unclear pattern. As regards the relationship between HDL-cholesterol, triglycerides and blood pressure, and insulin levels, all of these variables show an age adjusted significant association (Table 5). These differences, except for HDL-cholesterol, decrease slightly but consistently after adjusting for waist to thigh ratio, although remaining significant. This association decreases after adjusting for BMI instead of waist to thigh ratio, particularly for systolic and diastolic blood pressure, among females.

\section{Discussion}

This is the first large survey carried out in Italy to provide prevalence estimations of impaired glucose tolerance and previously undiagnosed diabetes according to the latest World Health Organization criteria based on the oral glucose tolerance test [3]. Despite a $58 \%$ participation rate, the results should be considered reliable as we investigated possible selec- 


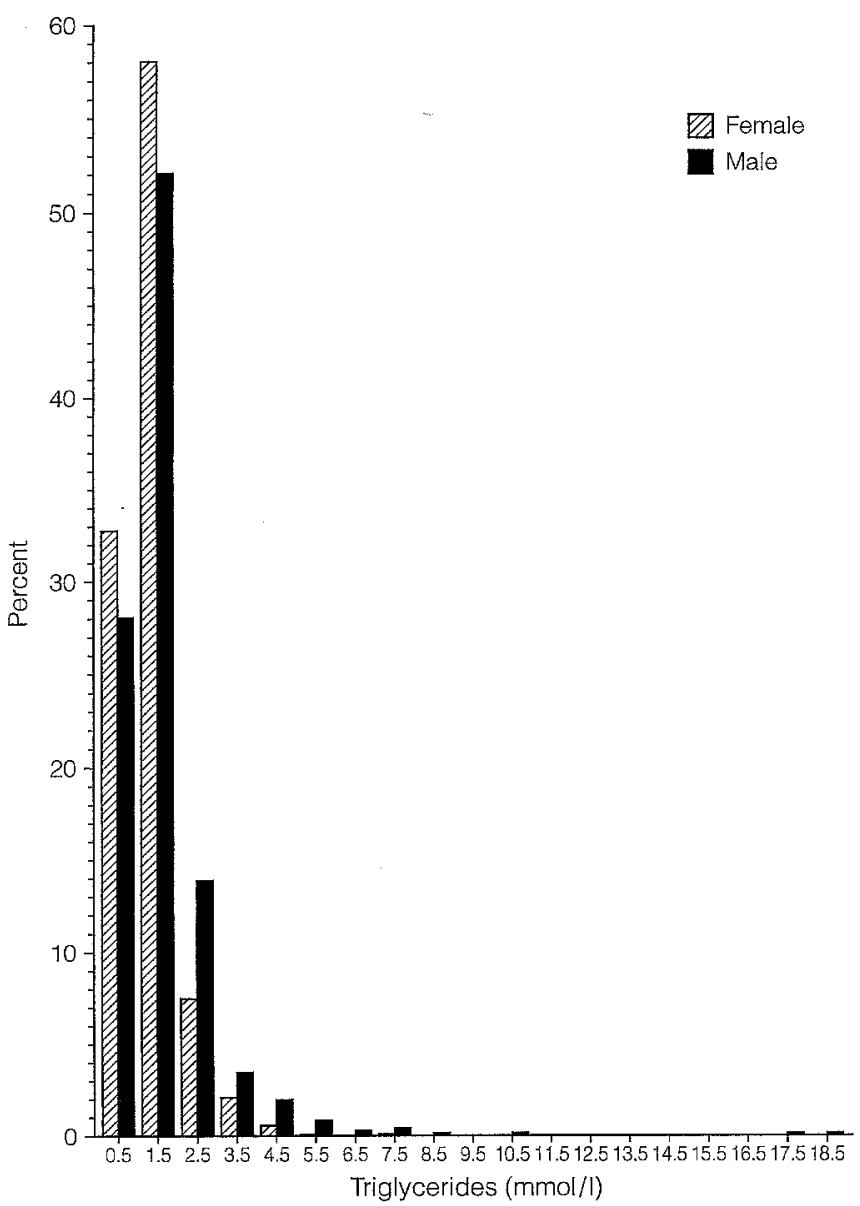

Fig. 5. Frequency distribution of plasma triglyceride levels in the population above the age of 44 years, by sex. Numbers on the $\mathrm{x}$-axis are the midpoints tion biases of the sample in terms of both diabetes family history and conditions of known diabetes. The former condition, though slightly unbalanced between participants and non-participants, was not considered to require any adjustment. On the contrary, awareness of diabetes status appeared to affect participation in a way requiring correction, with no simple relation to age or sex [2]. The prevalence estimation of $8.1 \%$ (males and females together) regarding diagnosed diabetes over 44 years is consistent with the figure of $8.0 \%$ resulting from a previous large investigation on known diabetes above 40 years, involving all the Cremona Health District population [6].

This study shows that the prevalence of total diabetes in the adult population of the Cremona area is quite high, accounting for $11.0 \%$ and $11.3 \%$ for males and females, respectively, above the age of 44 years. These adult specific rates roughly correspond to an overall prevalence of $4.5 \%$.

The corresponding figures adjusted for the world standard population (more developed countries) provide a prevalence of $3.7 \%$ for all ages and $10.7 \%$ for ages over 44 years. This overall prevalence appears similar to the most recent prevalence figures of some northern European countries, accounting for about $4 \%$ [7-11] while it appears lower than in Malta (9.2\% for males and $14.5 \%$ for females in the age 45-64 years), which provides the sole comparable data in southern Europe [1].

It is noteworthy that non-insulin-dependent diabetes and impaired glucose tolerance together affect

Table 4. Age-adjusted characteristics comparison of both diabetic and glucose intolerant subjects vs normal subjects, by sex

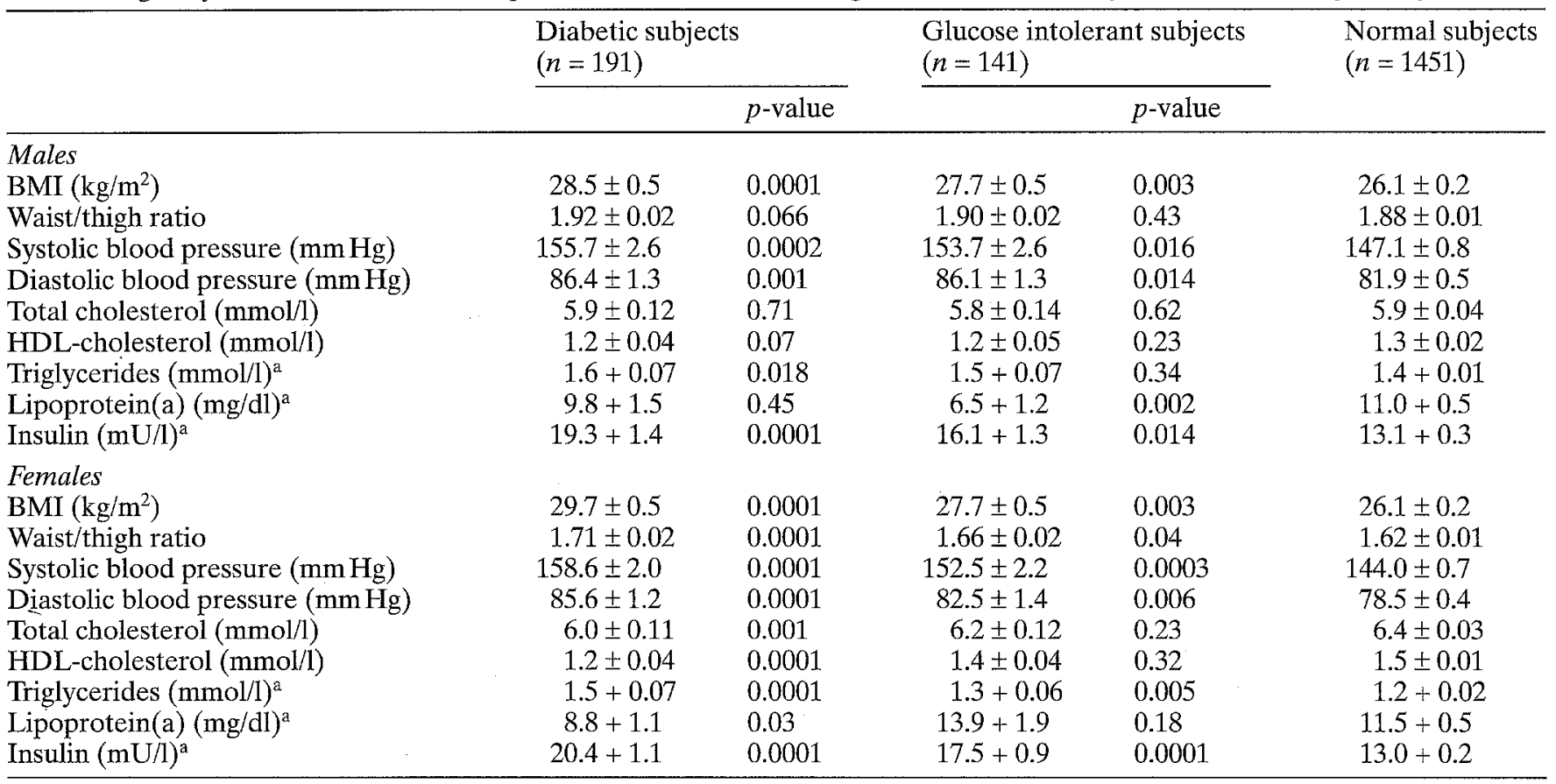

\footnotetext{
${ }^{a}$ Geometric mean.
}

Data shown as mean \pm SEM 
Table 5. Relationship between some cardiovascular risk factors and fasting insulin level, according to different standardisation models, by sex

\begin{tabular}{|c|c|c|c|c|c|c|c|}
\hline & \multirow[t]{3}{*}{ Model variables } & \multicolumn{3}{|l|}{ Females } & \multicolumn{3}{|l|}{ Males } \\
\hline & & \multicolumn{3}{|l|}{ Insulin } & \multicolumn{3}{|l|}{ Insulin } \\
\hline & & $<50$ th centile ${ }^{(\mathrm{a})}$ & $\geq 50$ th centile ${ }^{\mathrm{a}}$ & $\overline{p \text {-value }}$ & $<50$ th centile ${ }^{(a)}$ & $\geq 50$ centile $^{a}$ & $p$-value \\
\hline $\begin{array}{l}\text { HDL-Cholesterol } \\
(\mathrm{mmol} / \mathrm{l})\end{array}$ & $\begin{array}{l}\text { age } \\
\text { age + BMI } \\
\text { age + waist/thigh }\end{array}$ & $\begin{array}{l}1.53 \pm 0.02 \\
1.51 \pm 0.02 \\
1.52 \pm 0.02\end{array}$ & $\begin{array}{l}1.37 \pm 0.02 \\
1.39 \pm 0.02 \\
1.38 \pm 0.02\end{array}$ & $\begin{array}{l}0.0001 \\
0.0001 \\
0.0001\end{array}$ & $\begin{array}{l}1.40 \pm 0.02 \\
1.36 \pm 0.02 \\
1.39 \pm 0.02\end{array}$ & $\begin{array}{l}1.12 \pm 0.02 \\
1.16 \pm 0.02 \\
1.12 \pm 0.02\end{array}$ & $\begin{array}{l}0.0001 \\
0.0001 \\
0.0001\end{array}$ \\
\hline $\begin{array}{l}\text { Triglycerides } \\
(\mathrm{mmol} / \mathrm{l})^{\mathrm{b}}\end{array}$ & $\begin{array}{l}\text { age } \\
\text { age + BMI } \\
\text { age + waist/thigh }\end{array}$ & $\begin{array}{l}1.09+0.02 \\
1.11+0.02 \\
1.10+0.02\end{array}$ & $\begin{array}{l}1.37+0.02 \\
1.34+0.02 \\
1.34+0.02\end{array}$ & $\begin{array}{l}0.0001 \\
0.0001 \\
0.0001\end{array}$ & $\begin{array}{l}1.17+0.03 \\
1.20+0.03 \\
1.19+0.03\end{array}$ & $\begin{array}{l}1.67+0.04 \\
1.55+0.10 \\
1.64+0.04\end{array}$ & $\begin{array}{l}0.0001 \\
0.0001 \\
0.0001\end{array}$ \\
\hline $\begin{array}{l}\text { Systolic blood } \\
\text { pressure }(\mathrm{mm} \mathrm{Hg})^{\mathrm{c}}\end{array}$ & $\begin{array}{l}\text { age } \\
\text { age }+ \text { BMI } \\
\text { age }+ \text { waist } / \text { thigh }\end{array}$ & $\begin{array}{l}139.1 \pm 1.0 \\
140.8 \pm 1.1 \\
139.7 \pm 1.0\end{array}$ & $\begin{array}{l}144.6 \pm 1.1 \\
142.7 \pm 1.1 \\
143.9 \pm 1.1\end{array}$ & $\begin{array}{l}0.0003 \\
0.22 \\
0.006\end{array}$ & $\begin{array}{l}142.3 \pm 1.0 \\
142.7 \pm 1.1 \\
142.8 \pm 1.1\end{array}$ & $\begin{array}{l}148.2 \pm 1.2 \\
147.7 \pm 1.3 \\
147.7 \pm 1.2\end{array}$ & $\begin{array}{l}0.0002 \\
0.005 \\
0.003\end{array}$ \\
\hline $\begin{array}{l}\text { Diastolic blood } \\
\text { pressure }(\mathrm{mm} \mathrm{Hg})^{c}\end{array}$ & $\begin{array}{l}\text { age } \\
\text { age }+ \text { BMI } \\
\text { age }+ \text { waist } / \text { thigh }\end{array}$ & $\begin{array}{l}76.3 \pm 0.6 \\
77.0 \pm 0.6 \\
77.6 \pm 0.6\end{array}$ & $\begin{array}{l}79.7 \pm 0.7 \\
78.9 \pm 0.7 \\
79.4 \pm 0.7\end{array}$ & $\begin{array}{l}0.0002 \\
0.06 \\
0.003\end{array}$ & $\begin{array}{l}79.7 \pm 0.7 \\
80.3 \pm 0.7 \\
80.0 \pm 0.7\end{array}$ & $\begin{array}{l}83.5 \pm 0.7 \\
82.8 \pm 0.8 \\
83.1 \pm 0.7\end{array}$ & $\begin{array}{l}0.0002 \\
0.03 \\
0.002\end{array}$ \\
\hline
\end{tabular}

${ }^{\mathrm{a}}$ Insulin 50th centile $=14 \mathrm{mU} / 1 .{ }^{\mathrm{b}}$ Geometric mean. ${ }^{\mathrm{c}}$ Hypotensive drug treated subjects excluded.

Data shown as mean \pm SEM

about one subject in five and that insulin-dependent diabetes is quite negligible in this adult population.

As suggested by Balkau et al. [12], some of the diagnoses based on the OGTT could be due to an excessive alcohol consumption. As wine drinking is a normal habit in the investigated area, the common hepatic enzymes were determined for all participants, who were then classified according to a possible alcohol-dependent liver dysfunction. However, no significant association was found between glucose intolerance or diabetes and liver dysfunction.

Comparison of normal subjects with glucose intolerant or diabetic subjects confirms an unfavourable cardiovascular risk factor pattern among these latter categories. Body mass index remains one of the major risk factors associated with diabetes or impaired glucose tolerance. The high prevalence of obesity, among the investigated population could account, at least in part, for the high prevalence of the conditions of glucose metabolism abnormalities. We would like to stress the importance of systematically reporting BMI-specific prevalence rates, to allow more informative comparisons. Body mass index also seems to play a relevant role in the relationship between some common cardiovascular risk factors and fasting insulin levels, even independently of fat distribution, and has important implications in the prevention of cardiovascular diseases. Association of obesity to cardiovascular risk factors such as hypertriglyceridaemia, hypercholesterolaemia, hypertension and hyperinsulinaemia is well known. The findings of this paper support once again the vital role of life style in population health, and the need to increase the efforts to identify and apply effective intervention. It is in fact important to stress, as stated by Zimmet [13], that non-insulin-dependent diabetes can be prevented, and that strenuous risk factor intervention in subjects with this disorder can reduce their cardiovascular risk even if we do not fully understand their underlying biochemical and genetic mechanisms.

As far as the relationship between diagnosed and undiagnosed diabetes is concerned, the available data show that the proportion of unknown diabetes exhibits great variation among different countries [9, 11, 14-19], particularly when different Health Systems are operating. In our study its proportion resulted much lower with respect to the figures of 1 to 1 [14], up to now adopted in Italy.

Acknowledgements. The authors wish to thank all the people who participated to the survey; the administration of the 51th Local Health District of Lombardy for organisational facilities and financial support; Drs. R. Gelmi, and G. Spotti of the PMIP laboratory of Cremona, and Ms. F. Ragogna, Ms P. Sandoli and Ms S. Costa of the S. Raffaele research laboratory for their work in the biological determinations; the Cremona Diabetic Association and Mr. A.Mainardi, Ms. A.Poggi, Ms. E.Monteverdi, Ms. K.Bernabè, Ms. R. Filippone, Ms. P. Bolzoni, Ms. L.Ferrari for their invaluable support in the public relations with the study. This study has been in part supported by the National Research Council [(CNR) - Targeted Project "Prevention and Control Disease Factors"], Subproject 1 - contract n. 93.00664.PF41.115.05694.

\section{References}

1. Schranz AG (1989) Abnormal glucose tolerance in the Maltese. A population-based longitudinal study of the natural history of NIDDM and IGT in Malta. Diab Res Clin Pract 7: 7-16

2. Garancini MP, Calori G, Manara E et al. (1993) An Italian population-based study of the prevalence of diabetes: some methodological aspects. Diabete Metab 19: 116-120 
3. World Health Organization Expert Committee (1980) Second Report on diabetes mellitus. WHO Technical Report Series 646, Geneva

4. Annuario Statistico Italiano (1992). Sistema Statistico Nazionale. Istituto Nazionale di Statistica. Arti Grafiche Rubbettino, Battipaglia, pp. 56-62

5. Vu MT (1985) World Population Projection 1985. The Johns Hopkins University press, Baltimore, MD, pp 1-7

6. Gallus G, Garancini P (1991) Dati epidemiologici sul diabete mellito in Italia. Epidemiologia e prevenzione 48-49: $55-58$

7. Tuomilehto J, Nissinen A, Kivela SL et al. (1986) Prevalence of diabetes mellitus in elderly men aged 65 to 84 years in eastern and western Finland. Diabetologia 29: 611-615

8. Haavisto M, Mattila K, Rajala S (1983) Blood glucose and diabetes mellitus in subjects aged 85 years or more. Acta Med Scand 214: 239-244

9. Croxson SCM, Burden AC, Bodington M, Botha JL (1990) The prevalence of diabetes in elderly people. Diabet Med 8: $28-31$

10. Andersson DKG, Svardsudd K, Tibblin G (1991) Prevalence and incidence of diabetes in a Swedish community 1972-1987. Diabet Med 8: 428-434

11. Tuomilehto J, Korhonen HJ, Kartovaara L et al. (1991) Prevalence of diabetes mellitus and impaired glucose tolerance in the middle-aged population of three areas in Finland. Int J Epidemiol 20: 1010-1017
12. Balkau B, Eschwege E, Fontbonne A, Claude JR., Warnet JM (1992) Cardiovascular and alcohol-related deaths in abnormal glucose tolerant and diabetic subjects. Diabetologia 35: 39-44

13. Zimmet P (1992) Kelly West Lecture 1991 - Challenges in diabetes epidemiology - From west to the rest. Diabetes Care 15: 232-252

14. Harris MI (1993) Undiagnosed NIDDM: clinical and public health issues. Diabetes Care 16: 642-652

15. French JR, Boen JR, Martinez AM, Bushhouse SA, Sprafka JM, Goetz FC (1990) Population-based study of impaired glucose tolerance and type II diabetes in Wadena, Minnesota. Diabetes 39: 1131-1137

16. Wingard DL, Sinsheimer P, Barrett-Connor EL, McPhillips JB (1990) Community-based study of prevalence of NIDDM in older adults. Diabetes Care 13: 3-8

17. Mikkanen L, Laakso M, Uusitupa M, Pyorala K (1990) Prevalence of diabetes and impaired glucose tolerance in elderly subjects and their association with obesity and family history of diabetes. Diabetes Care 13: 1099-1105

18. Tuomilehto J, Nissinen A, Kivela SL et al. (1986) Prevalence of diabetes mellitus in eldery men age 65 to 84 years in Eastern and Western Finland. Diabetologia 29: 611-615

19. Simmons D, Williams DRR, Powell MJ (1989) Prevalence of diabetes in a predominantly Asian community: preliminary findings of the Coventry diabetes study. BMJ 298: $18-21$ 